\title{
New mobility strategies for the development of tourism in Sicily
}

\author{
G. Salvo, L. Caruso \& N. Santoro \\ Department of Energy, Transportation Research Group, \\ University of Palermo, Italy
}

\begin{abstract}
Tourism and transport is a well-established and inseparable pair. An area can increase the tourism in potentially own economy. This requires suitable accommodation and an adequate transportation system. A positive synergy effect is induced to increase the site. Transport is an important growth area for tourism, and as a result better functioning of transport facilitates access to sites, decreases the cost of transport and increases tourist flows.

In Sicily there is a wealth of artistic, archaeological and natural sites, generating a tourist flow during the year. Despite this, the network of connections and services is precarious. Residents and visitors are inaccessible to certain geographical areas. Often airport nodes are isolated for tourists as residents and connections to main destinations are by road transport, because rail is not competitive. Congestion of the main arteries increases negative externalities related to road transport and for tourists increases the negative perception of the journey. In this paper we propose guidelines for sustainable tourism, by analyzing the supply of mobility. The case study examines the reality of the stretch of waterfront in Western Sicily (Palermo to Trapani), introducing a faster shipping service to facilitate accessibility to tourist sites along the coast with a network of connections that includes airport nodes. Keywords: sustainable tourism, high speed craft, waterfront areas.
\end{abstract}

\section{Introduction}

Tourism is a sector that produces strong environmental impacts, with ecological and socio-economic consequences. This requires a global analysis, which allows 
us to study the dynamics of development, evaluating the benefits and impacts on various sectors with which it comes into contact.

In this context, land use with its tourist facilities and infrastructures and transport system became the basis for competitive tourism.

A place becomes a tourist destination when the market acquires awareness, which develops into tourism demand thanks to the ability to communicate the facilities offered.

The conditions for the local tourism development are essentially related to three categories of factors:

- natural and artificial resources;

- the organizational skills of the active population;

- the level of service offered in terms of accessibility to places.

The presence of a low-cost network to a destination, guides the choice of the tourists who, often, prefer one place rather than another due to economic factor and/or specific features present in places of destination.

The transport globalization involves a new idea of tourism. This turns to incoming, must be capable to offer travel deals to ensure "the emotion of an experience" [1].

Sicily is a region potentially competitive in terms of cultural, history and also natural and gastronomic factors. However, It suffers for lack of infrastructure, especially road transport network. This results in a deficit compared to other tourist destinations, also in experiential tourism.

Frequently, it happens that the time spent waiting and moving is long and unnerving. In fact, individuals have difficulty in meeting their demands and their needs, both the difficulty to have free time from daily life and for the car industry's pervasive accommodation. This last tends to envelop even the consumer in the spiral time and space of the holiday.

The maritime transport, especially shipping speed, is configured as an alternative to terrestrial transport system (road and rail) existing, already suffering from congestion.

In this way they can meet the needs of mobility for both people to move daily within the coastal area and for occasional users.

In particular, starting from the new frontiers of modern tourism, It has been analyzed that the current offer of transportation from the point of view of the existing technology of maritime means fast, bringing out their criticality and performance metrics.

It is analyzed the waterfront areas of Sicily, in particular the west side, and the possible benefits that may arise for the territory and for users.

\section{Touristic globalization and experiential tourism: the new frontiers of modern tourist}

Tourism is an important resource to develop the economy of a region. It is related to the need to travel and it can be considered as a moment of respite in the chaos of modern life. 
Taking into account the issue of tourism, implicitly it speaks about travel or displacement from/to the touristic destinations and, ultimately, about transport.

But transport and tourism are two aspects related between them. Planning and implementation of transport system must consider impacts caused by the mobility of people and goods related with tourism.

Likewise, tourism policies cannot overlook the aspects of travel from/to destinations and within each of the destinations themselves.

The organization and quality of transport services are an integral part of the tourism industry and increments, sometimes very significant, of tourists in an area are largely determined by the improvement of accessibility to the territory.

Although the accessibility to tourist areas depends by nature of the site, state of infrastructure and efficiency of transport systems, a new air transport low cost network flights allows the access to areas once considered outside the usual touristic circuits.

This has represented, during the last decades, the assertion of international mass tourism.

The air transport liberalization has favored the creation of low-cost airlines, bringing more competition in the sector, through prices considerably lower.

This has generated an increase of annual tourist movements and distances, modifying not only the traditional touristic offers but also the transport demand, generating the "globalization of tourism."

We ask ourselves why tourists travel from region of origin to a destination totally different for natural, environmental and cultural aspects and why they prefer particular destinations instead of others. Traveling is often the reason for relaxation, wellbeing and enjoyment.

The choice of destination becomes important when the visitor selects competitive elements between many alternatives characterized by:

- the ability to respond to different needs and motivations;

- the comparative cost;

- quality of services.

In the last few years, some tourists select the destination to visit in relation to the cost of transport, preferring the destinations more accessible to low-cost., rather than traditional destinations [2].

The tourist gives priority to the holidays that can offer, in relation to places, people and locations that he visited, not only the use of services but also new experiences or emotions. Travels, that combine many types of experiences during the space-time of a vacation, are of great success. The result is the leave of the old type of holiday, defined of "surface". So it is a necessary change in the management of tourist offers, that must adapt to the new type of demand and it must be seen not only as a destination but also as a product, that gives to the tourist a value added, defined as "experiential" [3].

Perception of places uses basically the visual senses and crossing fast replaces the total perceptual experience [4], so it is also important to consider this aspect, providing the tourist with experiential travel.

The experiences, in fact, produce sensations, emotions, values cognitive, behavioral and relational [1] and it is essential that policy-makers and tour 
operators, etc., analyze these factors, in order to guide the effects and thus make competitive the territory in which they manage.

In this context, tourism and marketing are inseparable (fig.1). The capacity to propose integrated marketing of the territory is a strategic aspect. The purpose is to win the individualism of local areas that disorients potential tourist, losing competitiveness in the global market.



Figure 1: $\quad$ Experiential tourism and marketing objectives.

For these reasons it is important for the development of Sicilian tourism to focus on these aspects, beginning with the transport experience that can be given to people.

The emotion of travel, in fact, should not be seen as just a moment to reach "Sicily" but also for mobility around the Island.

In this way the relation between historic resources, nature, etc. and the trip becomes an indissoluble element for the tourist, where the "movement" is an opportunity to elicit an "emotion".

\section{High speed craft}

During recent years there has been a development of technologies of high-speed marine vehicles. These vessels are used on a very short-distance and/or on medium-range routes, especially for passengers and car transport. In this charter we propose first the actual technologies and after the recent advances.

High Speed Craft (HSC) is a ship that reaches a speed over 20 knots, regulated by the HSC Code, proposed by the International Maritime Organization [5]. 
Table 1 describes technical details of HSC used in public transport [6].

Hovercraft is a vessel that provides an air cushion which allows it to move on different surfaces. The faster models have a speed of 50 knots, with 90 passengers. The endurance is about $200 \mathrm{~nm}$ for a speed of 24 knots, transporting 257 passengers.

Hydrofoils are HSC which, for hydrodynamic effect, rise up on the sea surface. The speed of hydrofoils is about 45 knots, draught $4.40 \mathrm{mt}$ with 250 passengers transported. There are problems with endurance and the adaptation of existing ports, especially due to the lower wings of hydrofoils [7].

Catamaran and Multi-Hull Vessels, different from the hydrofoil, allow transport of vehicles too. They consist of two or more hulls interconnected by a horizontal structure and they are called Trimarans when there are 3 hulls. The range of speed is 20-50 knots. Maximum passengers are 652 and the endurance is $600 \mathrm{~nm}$.

Mono Hull Crafts are HSC that consume more fuel and during exercise several problems occur, related to the wave motion generated near the coast due to high speed.

Table 1: $\quad$ Technical details of high-speed marine craft.

\begin{tabular}{ccccccccccc}
\hline & \multicolumn{2}{c}{$\begin{array}{c}\text { Length } \\
(\mathrm{m})\end{array}$} & \multicolumn{2}{c}{$\begin{array}{c}\text { Draught } \\
(\mathrm{m})\end{array}$} & \multicolumn{2}{c}{$\begin{array}{c}\text { Speed } \\
(\mathrm{knots})\end{array}$} & \multicolumn{2}{c}{$\begin{array}{c}\text { Endurance } \\
(\mathrm{nm})\end{array}$} & \multicolumn{2}{c}{ Passengers } \\
\cline { 2 - 11 } HSC & Min & Max & Min & Max & Min & Max & Min & Max & Min & Max \\
\hline Hovercraft & 10,15 & 51,00 & 0,27 & 2,60 & 23 & 50 & 120 & 750 & 16 & 334 \\
Hydrofoils & 18,55 & 43,50 & 0,30 & 4,88 & 30 & 50 & 130 & 320 & 40 & 400 \\
$\begin{array}{c}\text { High-Speed } \\
\text { Catamaran and } \\
\text { Multi-Hull } \\
\text { Vessels }\end{array}$ & 16,76 & 49,30 & 0,72 & 3,65 & 20 & 50 & 125 & 600 & 70 & 652 \\
$\begin{array}{c}\text { High-Speed } \\
\text { Mono Hull Craft }\end{array}$ & 22,78 & 48,50 & 0,80 & 2,83 & 22 & 38 & 200 & 300 & 64 & 450 \\
\hline
\end{tabular}

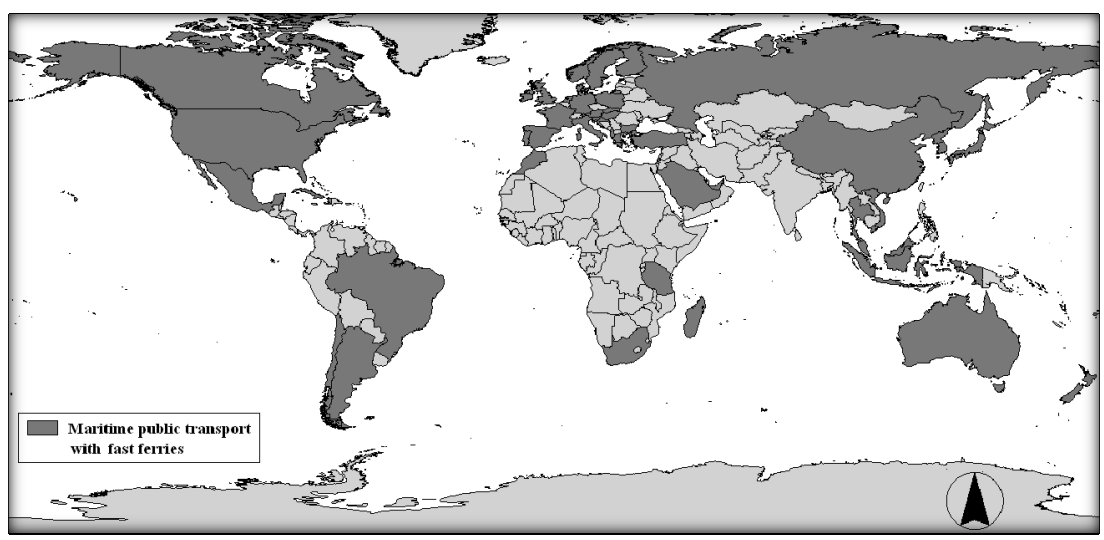

Figure 2: Distribution of HSC used for public transport in the world. 


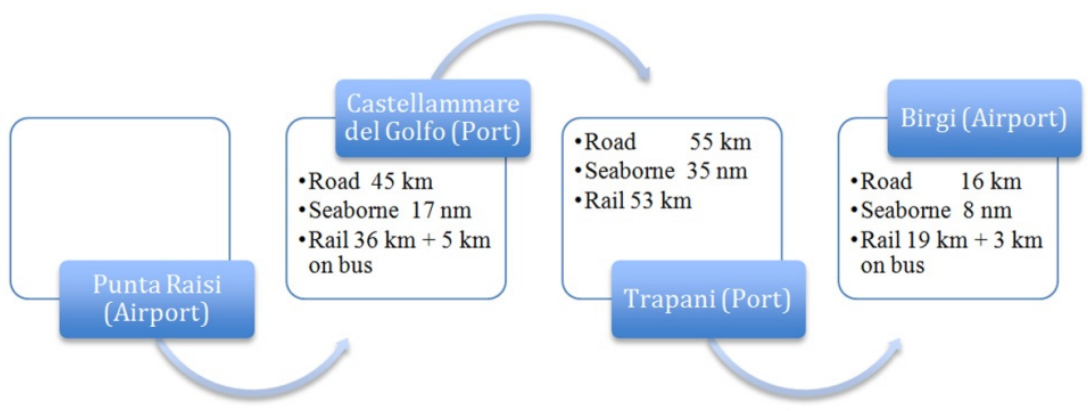

Figure 3: Distances in the area of study for several modes of transport.

Recent studies and research on HSC that appear in international literature and in conferences are about:

- materials [8];

- the design of high speed hulls (in general ship hydrodynamics) [9-11];

- hybrid systems for low environmental impacts;

- safety and operating characteristics of the various typologies of these highspeed marine vessels [12].

The following image (Fig. 4) shows some examples of HSC applications that operate scheduled services in the world [13].
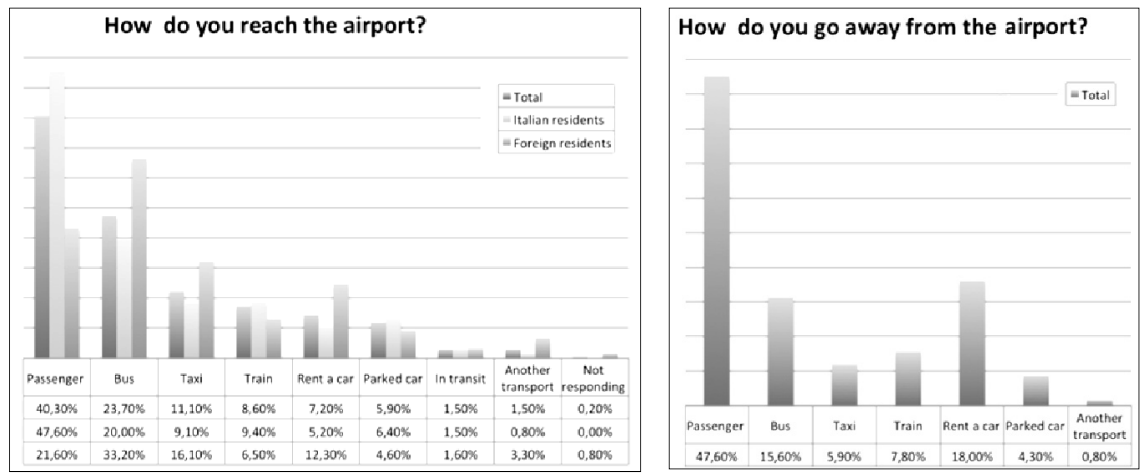

Figure 4: $\quad$ Analysis of modal split used to reach (in/out) Punta Raisi.

Cyclades Islands and the Canary Islands are some reality where you can move through a medium speed maritime for the airport.

Maritime and air transport services connect the Cyclades archipelago to the rest of the Greece and Europe. During the summer, the solutions increase to respond to the peaceful "invasion" of tourists.

The connections begin from the airport to the port, which connects with the islands. This also happens for the islands of the Canaries and the Balearics. The 
archipelago. All the islands have an airport, except for El Hierro and La Gomera, which have internal connections (only between the islands).

To get to Tenerife, Gran Canaria and Lanzarote there is a connection from the port of Cadiz with the company Acciona Transmediterrànea.

The Balearic Islands have connections with the airports of Mallorca, Menorca and Ibiza. For example the island Formentera is only connected by hydrofoil to Ibiza.

In this paper we present some innovative HSC. Trimaran and Pentamaran hull, for passenger and vehicle transportation, seem to be appreciated by international studies and proposals for non-conventional high-speed marine vehicles [14].

The research on Hybrid systems is oriented for low environmental impact, through craft with photovoltaic panels.

For example "Planet Solar" [15] is a catamaran length 30mt, with a surface of 537 square meters, covered by photovoltaic panels. The speed is 8 knots with a maximum speed of 14 (tab. 2). The sun energy is retained in batteries, so it is possible to also navigate during the night (autonomy 3 days).

Table 2: $\quad$ Technical details of "Planet Solar".

\begin{tabular}{lcc}
\hline \multicolumn{1}{c}{ Technical details } & Value & Units of measure \\
\hline Length & 31 & $\mathrm{~m}$ \\
Width & 15 & $\mathrm{~m}$ \\
Height & 6.10 & $\mathrm{~m}$ \\
Length with flaps & 35 & $\mathrm{~m}$ \\
Width with flaps & 23 & $\mathrm{~m}$ \\
Crew & 4 & persons \\
Passengers & 40 & persons \\
\hline
\end{tabular}

Another research is about the use of sails or more mobile sails, covered with photovoltaic panels [16].

Unresolved aspects for high-speed ships or, at least aspects requiring deeper investigation, are still work in progress.

\section{Case study}

This study proposes a new transport mode between the airports of Palermo and Trapani, integrating the actual mobility offers and taking advantage that airports are located near the coast.

The airports of Punta Raisi (Palermo) and Birgi (Trapani) in western Sicily are able to promote economic developments, tourisms and socials for these areas.

The statistical tourist flow (GESAP) report that, in 2010, the airport of Punta Raisi, between departures and arrivals, recorded 4,342,227 passengers [17]; while from the airport of Birgi, in 2009, 1,069,528 passengers arrived and the numbers continue to grow [18]. 
This zone is about $60 \mathrm{~nm}$ and covers part of the metropolitan area of Palermo and province of Trapani (fig. 2).

It is densely urbanized and there are many itineraries of historical, gastronomic and natural interests.

The actual transport, accentuated by inefficiency of the rail system, are not able to supply the mobility demand generated by activities of this territory, causing daily congestion on the roads.

So the airport is an independent and isolated transport hub.

Figure 3 shows the results of a survey (year 2010) carried out in Palermo Airport on a sample of 1,294 passengers, with regard to the means of transport used to reach the airport [19].

The results show that private transport is prevailing over public transport.

It is necessary to enforce the public transport, making them efficient, economic and integrated. In this way tourism can be experiential, involving people already on the move.

The solution should be the introduction of fast sea shipping, creating a touristic product suitable for the existing demand that is becoming more so.

The target is to use a suitable ship for speed, capacity, autonomy, etc., operating at an optimal commercial speed that should reduce the number of berthings.

We propose the use of HSC already in operation in Sicily, because the prototypes at low environmental impact are not competitive for commercial applications. In this way this service can be considered a widening of the existing maritime transport system.

Hydrofoil is the suitable HSC for this application. In fact the adaptation of existing ports for these ships requires limited resources.

Moreover, mobility demands concern to people that must go to the airports, therefore it is not priority the transport of vehicles.

In this study a variety of places were identified that can take the speed of transport and are easily accessible through public transport. Four stopping points have been identified [20]:

- Punta Raisi (Project);

- Castellammare del Golfo;

- Trapani;

- Birgi (In expansion).

Palermo airport is located in the Punta Raisi, $35 \mathrm{~km}$ from the center of Palermo, along the A29, after the exit of Cinisi. There are several services of transport that connect the airport with Palermo, covering the time periods of arrival and departure of flights, but there is no place to berth from the sea.

This node represents the local airport in the metropolitan area of Palermo and western Sicily, also for national and international connections of short-range. There is no place to berth from the sea.

Figure 5 shows an idea of location originated from the proximity of the airport [21]. The hypothesis provides a service of $300 \mathrm{mt}$. 


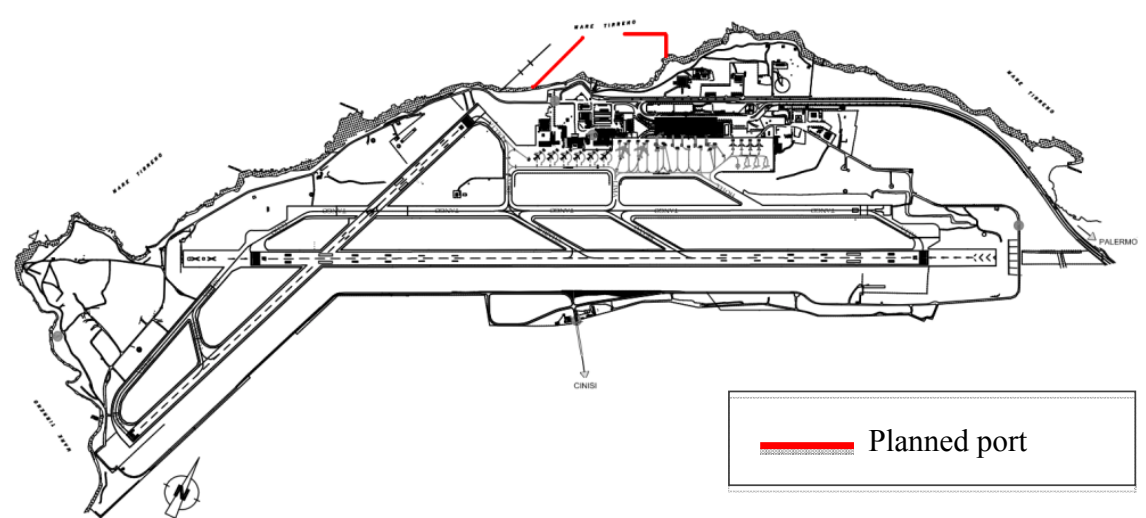

Figure 5: Port location of Punta Raisi.

Castellammare del Golfo (Port) is located half way between the port of Trapani and Palermo. On the east, the Castle Quay is internally equipped with quays and mooring rings.

Actually it is used for pleasure boats, so it could be a starting point as a tourist destination and as a connection to the interior West.

This decision brought consideration to examine the feasibility of an expansion and a connection with the airport infrastructure in western Sicily, to improve the mobility of one of the most depressed areas of the south.

The port of Trapani has a close connection with the city and its historic center, for historical, cultural and geographical reasons. Drills, said "port city", was created and developed around its own port, since ancient times.

Many companies operating within the harbour are able to provide various port facilities and it is an ideal place to receive maritime assets of different types and sizes. Also it offers services to destination, excellent level and easy to use.

In order to berth at Trapani there are quays of a total length of 1.650 meters and numerous infrastructures are near, such as the train station and airport of Trapani-Birgi. For those arriving at the port of Trapani, it is located near the centre of the city.

The airport of Trapani - Birgi "Vincenzo Florio" is a military berthing open to traffic and passenger flows have increased in the last few years, through low cost airlines. Accessibility is guaranteed by road transport because the nearest train station is Mozia-Birgi ( $3 \mathrm{~km}$ from the airport). There are place to berth near this airport which needs expansion.

\section{Conclusions}

The purpose of this paper was to propose an alternative mode of transport to connect Punta Raisi and Birgi airports, proposing a fast maritime connection from an airport to another of the western Sicily.

The assumption of this study was to propose the enhancement of existing berths, transforming them into strategic interchange nodes and tourism. 
The modern HSC, especially hydrofoils, are able to offer a regular and comfortable service to tourists.

These nodes are mainly sites that including customs, functions, streams: a synthesis of space and community.

The project, in addition to the enforcing of the port functions (increasing), describes the development, to the transport system, itineraries of monumental historical and touristic that they are very attractive.

\section{References}

[1] Del Gatto S., Mastrogiorgio A., Stimoli olfattivi e preferenze del consumatore: un'analisi empirica nel settore turistico. Congresso Internazionale “Le Tendenze Del Marketing”, Venezia, pp.3-4, 2006.

[2] Salvo G., Il ruolo dei sistemi di trasporto: Dalla competizione alla cooperazione. Convegno Homo Movens, Palermo, p.1-15, 2011.

[3] Billi S., Giannetti E., Giannone M., L'esperienza del prodotto turistico: per una misurazione dell'esperenzialità nelle aree protette siciliane. Rivista interdisciplinare di studi ricerche e formazione, pp.1-12, 2004.

[4] Calabi D. A., Design della comunicazione e territorio: uno strumento strategico di relazione. Strategic Design Research Journal, pp.7 -10, 2009.

[5] International Marittime Organization IMO, International code of safety for high speed craft 2000, 2001.

[6] Jane's, High-Speed marine craft 1994-95, Janes Information Group; 27th edition, 1994.

[7] Caruso L. (2011). Mezzi innovativi per il trasporto marittimo veloce. I workshop Regionale degli Assegnisti di Ricerca Siciliani "Nella rete del sapere: ricerca, istituzioni e società in Sicilia", Palermo, 2011.

[8] Torrez J. B., Light-Weight Materials Selection for High-Speed Naval Craft. Submitted to the Departments of Mechanical Engineering on May 11, 2007 in partial fulfillment of requirements for the Degrees of Naval Engineer and Master of Science in Civil and Environmental Engineering, 2007.

[9] Brizzolara S., Federici A., Super-Cavitating Profiles for Ultra High Speed Hydrofoils: a Hybrid CFD Design Approach. IX HSMV, Naples, 2011.

[10] University of Genova - Dipartimento di Ingegneria Navale e Tecnologie Marine, Hydrodynamic characteristics of innovative high-speed vessels. European and national transport research programmes across Europe Transport Research knowledge. Projects \& Analysis, 2005.

[11] Collu M., Patel M. H., Trarieux F., High speed marine vehicles with aerodynamic surfaces: development of a dynamic model for a novel configuration. Cranfield Multi Strand Conference, Cranfield, 2008.

[12] Antão P., Guedes S. C., (2008), Causal factors in accidents of high-speed craft and conventional ocean-going vessels. Reliability Engineering and System Safety, pp.1292-1304, 2008.

[13] FAST FERRY, http://www.fastferryinfo.com/ 
[14] Center for the Commercial Deployment of Transportation Technologies, Route/Mission Depend Prediction Program for Rational Structural Dynamic Loads for High-Speed Multihulls, Phase II-B. Final Report. Submitted to Office of Naval Research, Arlington, 2008.

[15] PLANET SOLAR, http://www.planetsolar.org

[16] SOLAR SAILOR, http://www.test.solarsailor.com.au

[17] GESAP - Aeroporto di Palermo, Traffic statistics Jan-Dec 2010, 2010.

[18] AIRGEST, http://www.airgest.it/

[19] Doxa, Profilazione passeggeri aeroporto di Palermo, 2010.

[20] Regione Siciliana, Dipartimento Turismo, Sport e Spettacolo. Porti di Sicilia. Quarantadue approdi per conoscere il cuore dell'Isola, 2005.

[21] Salvo G., Caruso L., The fast maritime transport for the waterfront revitalization of the airports in Western Sicily. Portus Plus 2-2011, 2011. 